\section{Edycasáa

ARTIGO

\section{Editores}

Maria Inês Côrte Vitoria

PUCRS, RS, Brasil

Pricila Kohls dos Santos

PUCRS, RS, Brasil

\section{Equipe Editorial}

Carla Spagnolo

PUCRS, Brasil

Rosa Maria Rigo

PUCRS, Brasil

\title{
A leitura de contos como recurso didático para a formação do leitor em Clube do Livro a partir da Pedagogia Histórico-Crítica
}

\author{
Reading tales as teaching method for the Club Reader
} based on Historical-Critical Pedagogy

\author{
Karla Raphaella Costa Pereira ${ }^{a}$ \\ Maycon Maia Rodrigues ${ }^{b}$ \\ Frederico Jorge Ferreira Costa ${ }^{c}$
}

\section{RESUMO}

O presente artigo trata de uma proposta de intervenção pedagógica em escola pública estadual do Ceará por meio da elaboração e execução de um clube de leitura intitulado Clube do Livro. Projeto realizado com o apoio do Programa Interinstitucional de Bolsas de Iniciação à Docência (Pibid) e idealizado por um grupo de professores da escola na qual o clube está inserido. A metodologia de pesquisa utilizada é apresentada em duas fases: a primeira, bibliográfica, apresenta o referencial teórico utilizado na elaboração do projeto Clube do Livro; a segunda descreve a forma como a ação é executada. O Clube do Livro enquadra-se como pesquisa-ação por propor uma prática que intervenha no ambiente no qual se realiza a pesquisa e que seja realizada pelos membros que compõem esse grupo. Pedagogicamente, o projeto advoga-se circunscrito na Pedagogia Histórico-Crítica. A relevância desse projeto dá-se na oportunidade de oferecer aos educandos instrumentalização para o acesso a obras literárias de qualidade.

Palavras-chave: Recurso didático; Pedagogia histórico-crítica; Clube do Livro

\section{ABSTRACT}

This article deals with a proposal of pedagogical intervention in a state public school in Ceará, through the elaboration and execution of a reading club called Club Reader. The project is carried out with the support of

\footnotetext{
a Doutoranda e Mestra em Educação pelo Programa de Pós-Graduação em Educação (PPGE/UECE). Bolsista CAPES/BRASIL.

b Mestrando em Filosofia pela Universidade Federal do Ceará (PROF-FILO/UFC). Professor da Rede Estadual de Educação do Ceará (SEDUC/CE).

c Doutor em Educação. Professor da Universidade Estadual do Ceará (FACEDI/UECE). Membro do Programa de Pós-Graduação em Educação (PPGE/UECE) 
the Interinstitutional Scholarship Initiative Program (Pibid) and was conceived by a group of teachers from the school in which the club is inserted. The text exposes the methodology of research in two phases: the first one, bibliographical, presents the theoretical reference used in the elaboration of the Club Reader project; the second describes how the action is performed. The Club Reader is framed as an action research for proposing an action that intervenes in the environment in which the research is carried out, as well as being performed by the members that make up this group. Pedagogically, the project is advocated circumscribed in HistoricalCritical Pedagogy. The relevance of the Club Reader project is given in the opportunity to offer students the instrumentalization for access to quality literary works.

Keywords: Didactic resource; Historical-critical pedagogy; Club Reader

\section{Introdução}

Escinting

ste artigo objetiva apresentar elementos iniciais de construção de uma proposta pedagógica para o que se intitulou Clube do Livro, uma atividade extracurricular realizada em escola pública da rede estadual de educação do Ceará, localizada em Fortaleza. Ação elaborada e executada pelos autores deste texto de forma colaborativa e coletiva, visando formar o estudante da rede pública como leitor, bem como propiciar experiência profissional ao professor além da sala de aula.

O projeto realiza encontros periódicos entre professores da escola e de outras instituições, alunos dos cursos de licenciatura em Ciências Humanas vinculados ao Programa Institucional de Bolsa de Iniciação à Docência (Pibid) da Universidade Estadual do Ceará, alunos e ex-alunos secundaristas (público-alvo do projeto), bem como demais membros da comunidade escolar que se fazem interessados. A metodologia desenvolvida nos encontros consiste na leitura compartilhada de textos literários de diversificados gêneros. No caso do projeto ora exposto, a proposta de trabalho visa utilizar obras do gênero conto.

Dois movimentos de exposição do projeto são aqui apresentados: primeiramente, a pesquisa bibliográfica que fundamenta todo o processo e, notadamente, embasa a compreensão literária do conto como um gênero textual; em seguida, a proposta de intervenção pedagógica, ou seja, como o projeto se realiza e qual a contribuição que proporciona à aprendizagem do educando, visando sugerir a outros professores sua realização.

A primeira parte possui como metodologia a pesquisa teórico-bibliográfica centrada no debate acerca da teoria do conto e sua relação com a realidade social; na segunda, enquadra-se a pesquisa-ação, tendo em vista que: 1) o objeto, a saber, a proposta pedagógica do Clube do Livro em seu trabalho com contos literários, é resultado da ação 
dos integrantes do próprio grupo; 2) os pesquisadores que ora apresentam esta pesquisa são membros do grupo em análise (THIOLLENT, 1992).

Quanto à teoria da arte e da literatura, o projeto assume as proposições de György Lukács, pós-1930, nas quais explicita, juntamente com Lifshitz, que há uma estética marxista articulada com as proposições de Marx e Engels sobre a totalidade sócio-histórica e resultado da ação dos homens. Além disso, dialoga com Julio Cortázar (1999) e, através de Nádia Battella Gotlib (2006), com Julio Casares, Edgar Allan Poe, Tchekhov, dentre outros mestres do conto.

A Teoria do Conto não é campo de tranquila transição, pois não há definição assumida com unanimidade. Ao contrário do que pode defender uma leitura simplista do conto, afirmando que é um gênero moderno, sua origem remonta às baladas da pré-história (GOTLIB, 2006). A modernidade do conto é, evidentemente, fruto de sua evolução histórica e foi ocorrendo com significativas mudanças no estilo dos contistas, porém há que se ter em mente que há neste especificidades; caso contrário, não seria possível reconhecer a permanência do conto. Mário de Andrade (apud GOTLIB, 2006) defende que o questionamento o que é o conto é um inábil problema de estética literária. Julio Cortázar (1999) considera que não é inútil falar do conto em abstrato, como gênero textual, percebendo-se, entretanto, que não há leis sobre a especificidade do conto e sim pontos de vista. Alguns desses, discutidos por Gotlib (2006), são expostos na primeira parte deste artigo.

Marx (2010) observa que os sentidos humanos não são produtos apenas das naturezas orgânica e inorgânica, mas são sociais e, portanto, foram, como tudo que é humano, objetivados historicamente. Assim, a maneira como o homem capta a realidade, através dos sentidos, é a forma humana histórica de captar o mundo. As impressões sensoriais precisam, então, ser educadas para fruir a leitura literária e dessa adquirir aprendizados. É necessário ter contato com a arte para apreciar a arte; educar os sentidos para tal tarefa.

Partindo da Pedagogia Histórico-Crítica, proposta pelo educador brasileiro Dermeval Saviani, a implementação do Clube do Livro oferece aos estudantes os instrumentos, entendidos como conhecimentos basilares sobre a literatura e experiências empíricas com a leitura literária, na medida em que

Não é favor algum ao povo propor-lhe uma literatura assimilável sem esforço, passivamente, como quem vai ao cinema ver filmes de caubóis. O que se deve fazer é educá-lo, e isto numa primeira etapa é tarefa pedagógica e não literária (CORTÁZAR, 1999, p. 362).

O projeto ora investigado e apresentado incumbe-se deste duplo papel: educar os sentidos para a apreciação literária e proporcionar acesso às obras literárias. A literatura em si possui caráter educativo. E o que cabe à escola 
é proporcionar condições de acesso, objetivas e de conhecimento. É indispensável destacar que esse papel deve ser assumido pelo Estado, proporcionando formação e condições pedagógicas para a atuação do professor.

\section{Algumas perspectivas da Teoria do Conto: fundamentação teórica}

A pesquisa bibliográfica consistiu na apreensão de análises acerca do que caracterizaria um conto, já que este é um gênero textual com limites e características bem demarcados. Como dito anteriormente, não há unanimidade sobre o conto entre teóricos, críticos literários e escritores. Segundo Cortázar (1999, p. 348), apesar de não ser possível estabelecer leis definidoras do conto, é preciso se chegar a uma ideia viva do que este representa: "[...] existem certas constantes, certos valores que se aplicam a todos os contos, fantásticos ou realistas, dramáticos ou humanísticos". Este tópico faz um esforço para expor alguns pontos de vista sobre o conto.

Segundo Gotlib (2006), algumas questões rodeiam a busca pela especificidade do conto: "O conto teria característica específica de gênero?", "o que faz com que os contos continuem contos apesar das mudanças que naturalmente foram experimentando no curso da história?". A autora apresenta - e dela se seguirá o raciocínio - as posições de grandes contistas da literatura universal, sob a advertência de que "tratar da teoria do conto é aceitar uma luta em que a força da teoria pode aniquilar a própria vida do conto" (GOTLIB, 2006, p. 11).

Antes de seguir com as especificidades de cada contista/teórico, é importante destacar o que é recorrente em cada um deles: a base de diferenciação do conto é que ele é curto. O que não significa que a ação a mostrar não seja longa, mas, mesmo longa, é melhor apresentada na forma contraída. Em comparação com o romance e com a novela, o conto é considerado curto, ainda que em extensão possa se aproximar da novela. É pela capacidade de apresentar um aspecto da realidade, específico, sem isolá-lo da totalidade social, que se afirma ser o conto uma obra de arte.

Segundo Julio Casares (apud GOTLIB, 2006), há três acepções de conto: relato de um acontecimento, narração oral ou escrita de um acontecimento falso e fábula que se conta às crianças para diverti-las. O ponto em comum entre essas acepções é que são narrativas. Para Claude Brémond (apud GOTLIB, 2006, p. 12), a narrativa consiste "[...] em um discurso integrado numa sucessão de acontecimentos de interesse humano na unidade de uma mesma ação". Nádia Battella Gotlib (2006, p. 12), então, afirma que:

De fato, toda narrativa apresenta: 1. uma sucessão de acontecimentos: há sempre algo a narrar; 2. de interesse humano: pois é material de interesse humano, de nós, para nós, acerca de nós: “e é em relação com um projeto humano que os acontecimentos tomam significação e se organizam em uma série temporal estruturada"; 3. e tudo "na unidade de uma mesma ação". 
Contar estórias, entretanto, não é a única condição do contista. O conto literário precisa ser contado de forma que a criação, a arte da escrita, não se identifique com qualquer relato, com qualquer documento. Vladimir Propp (apud GOTLIB, 2006), na Morfologia do conto, revela que há formas para determinar as constantes do conto. Segundo ele, há cerca de 150 elementos, 31 funções e sete personagens. As funções seriam as ações dos personagens; entretanto, independentes destes: as mesmas ações podem ser exercidas por personagens diferentes. Em

"O Chapeuzinho Vermelho", por exemplo, há a função da ausência de um dos membros da família (o Chapeuzinho), que é a primeira função determinada por Propp. E há também uma ordem que lhe é dada (pela mãe); o engano da vítima (pelo lobo, que irá devorá-la); a salvação do herói (pelo caçador); a punição do antagonista (morte do lobo) (GOTLIB, 2006, p. 18-19).

Dessa maneira, a definição de conto maravilhoso é dada por Propp (apud GOTLIB, 2006, 19):

Podemos chamar conto maravilhoso, do ponto de vista morfológico, a qualquer desenrolar de ação que parte de uma malfeitoria ou de uma falta (...), e que passa por funções intermediárias para ir acabar em casamento (...) ou em outras funções utilizadas como desfecho.

Propp não esquece que a realidade pode modificar ou transformar o conto. É ele, também, que aponta as duas fases de evolução do conto: uma primeira, em que o conto e o relato sagrado se confundem; e uma segunda, quando o conto se libera da religião e passa a ter vida própria. Não é possível, segundo Gotlib (2006), determinar quando se dá essa transformação. A autora afirma, ainda, que os estudos de Propp estimularam outros na área da linguística, da antropologia, da etnografia, do folclore e da semiótica, a exemplo de Greimas.

A discussão que Nádia Gotlib (2006) apresenta, ao debater o conto como gênero, parte de experiências concretas, ou seja, ela expõe o que grandes contistas teorizaram sobre o próprio exercício, as obras, bem como sobre outros contos. Tal escolha é relevante e coerente com as conclusões que ela apresenta ao final da obra como é demonstrado ao final deste tópico -, pois não é possível uma teoria do conto fechada. Parte-se de exemplos concretos, reais, para entender idealmente. Destaca-se que a exposição que segue tem como referência a obra supracitada.

Para Edgar Allan Poe, há uma relação entre a extensão do conto e o efeito, ou seja, a reação que este consegue provocar no leitor. O efeito que a leitura deve causar é critério para a composição literária, é uma excitação extensa e transitória, por isso é necessário dosar a obra para que não se perca a excitação. Segundo ele, 
[...] no conto breve, o autor é capaz de realizar a plenitude de sua intenção, seja ela qual for. Durante a hora da leitura atenta, a alma do leitor está sob o controle do escritor. Não há nenhuma influência externa ou extrínseca que resulte de cansaço ou interrupção (POE apud GOTLIB, 2006, p. 27).

O autor precisa ter consciência de qual o efeito que deseja causar no leitor, atentando para a economia dos meios narrativos, aspecto aceito e reproduzido por diversos contistas. A economia dos meios narrativos de Poe trata do esforço do autor em alcançar, no leitor, o máximo de efeitos com o mínimo de recursos; trata-se de eliminar os excessos. Julio Cortázar (apud GOTLIB, 2006, p. 28) sintetiza a teoria de Poe da seguinte forma: "Um conto é uma verdadeira máquina literária de criar interesse". Um leitor de Poe compreende bem essa afirmação. Ainda segundo Cortázar, o que causa tal interesse é o acontecimento. A composição deve confluir para tal. "Complementando e contrariando Poe, considere-se, pois, que nem toda obra é só deliberada ou se faz só por um processo mecânico, de execução consciente de um plano pré-estipulado. Nem a de Poe, segundo Cortázar” (GOTLIB, 2006, p. 31).

Além disso, há questionamentos sobre a produção do efeito no conto de Poe: como controlar esse efeito, já que leitores diferentes podem vivenciar efeitos diferentes? Outros tentam avançar sobre a caracterização desse efeito. Entretanto, Poe permanece considerado um dos maiores contistas e mestres na arte de prender o leitor. De toda forma, como dito anteriormente, aceita-se a defesa da condensação, concentração ou compactação do conto.

Tchekhov, contista e dramaturgo russo, não desenvolveu uma teoria do conto, porém explicitou em sua correspondência uma crítica a outros escritores, permitindo, segundo Gotlib (2006), uma compreensão do que ele defende acerca da escrita de contos. Assim como Poe, Tchekhov prima pela brevidade e critica, inclusive, Górki pela falta de contenção: "O Sr. é como o espectador num teatro que manifesta seu entusiasmo de maneira tão desenfreada que impede a si e os outros de ouvirem" e, ainda, "graciosidade é quando alguém, numa determinada ação, utiliza o mínimo de movimento. Mas nos gestos que o senhor faz, sente-se o excesso" (TCHEKHOV, 2006, p. 33).

O conto, para o contista Tchekhov, precisa causar efeito no leitor, que deve ser mantido em suspense. Esse autor insere um fato novo na narrativa que não precisa ser extraordinário. Efeito também chamado pelo russo de impressão total. Além disso, o conto deve ser claro, o leitor precisa entender de imediato o que o autor quer dizer; deve ser forte, marcar o leitor, prendendo-lhe a atenção; e deve ser compacto, condensando os elementos; além de objetivo: "Quanto mais objetivo, mais forte será o efeito" (TCHEKHOV, 2006, p. 32, grifos dos autores do artigo).

Outro aspecto que merece destaque nas análises de Tchekhov é sua proposta de realismo: representar a verdade é, para ele, 
[...] a absoluta liberdade do homem, liberdade da opressão, dos preconceitos, ignorância, paixões, etc. E para denunciar uma situação condenável. Meu objetivo é matar dois pássaros com uma só pedra: pintar a vida nos seus aspectos verdadeiros e mostrar quão longe está da vida ideal (TCHEKHOV apud GOTLIB, 2006, p. 34).

O realismo, assim entendido, aproxima-se da perspectiva lukacsiana, apoiada nas proposições de Marx e Engels em sua vasta obra. Os autores entendem a arte como uma representação do real, não como cópia exata nem como manifestação apenas da vontade do autor. O bom contista é justamente aquele que consegue representar, no texto, uma realidade mais ampla do que a que ele figura. Um bom conto abre-se para um mundo mais amplo, possibilita a compreensão de uma realidade para além do exposto, do narrado. Nas palavras de Cortázar (1999, p. 355), “[...] são aglutinantes de uma realidade infinitamente mais vasta que a do mero episódio que contam, e por isso nos influenciaram com tal força que a modéstia do seu conteúdo aparente, a brevidade do seu texto, não permite suspeitar".

É preciso ainda expor as digressões de James Joyce e a produção de Clarice Lispector, já que estas são apresentadas por Gotlib. Joyce defende que um dos momentos especiais do conto é a epifania, ou seja, a manifestação espiritual súbita em que um objeto se desvenda ao sujeito,uma percepção reveladora da realidade. Para Joyce, a epifania seria um dos momentos da beleza:

O primeiro deles seria o da integridade, quando se percebe a coisa enquanto obra integral. Este primeiro quesito permite reconhecer a coisa como sendo uma, e não outra. O segundo, o da simetria, permite considerar o objeto como um, em si mesmo, nas suas partes e no seu todo, na relação consigo mesmo e com outros objetos. E pelo terceiro, a epifania, a coisa torna-se ela mesma (GOTLIB, 2006, p. 39).

De acordo com Olga de Sá (apud GOTLIB, 2006), a epifania em Clarice Lispector ocorre partindo-se de uma estória aparentemente simples, de um momento da personagem que passa por uma experiência que gera uma desordem interior para, em seguida, retornar à ordem com algumas perdas e ganhos da experiência ou vivência. Geralmente, em Clarice Lispector, a experiência tem um caráter místico, gnóstico, filosófico ou estético. Tal entrecho insere-se na construção moderna do conto; o momento especial é interior. Apesar dessa característica moderna, o conto de Lispector ainda guarda a estrutura clássica do conto, em Gotlib (2006, p. 40), exemplificada com o conto Amor: "1. o início (Ana vai às compras e aparece envolvida na rotina doméstica); 2. o desenvolvimento (Ana mergulha na experiência de crise desde quando vê o cego até fugir correndo do Jardim Botânico); 3. o final (Ana volta para a rotina doméstica)". 
Já Machado de Assis é trazido como um caso à parte:

Porque os contos de Machado traduzem perspicazes compreensões da natureza humana, desde as mais sádicas às mais benévolas, porém nunca ingênuas. Aparecem motivadas por um interesse próprio, mais ou menos sórdido, mais ou menos desculpável. Mas é sempre um comportamento duvidoso, que nunca é totalmente desvendado nos seus recônditos segredos e intenções (GOTLIB, 2006, p. 56).

Nadine Gordimer (apud GOTLIB, 2006, p. 41) compreende o conto como um corte no fluxo da vida; representa o real como flashes de luz intermitentes que lembram o piscar de vagalumes. Gotlib (2006, p. 41) adverte que essa concepção, assim como a do conto como um engendrar de epifanias, consegue explicar um ou outro conto, mas não o conto enquanto gênero textual.

O Machado de Assis contista representa a realidade com sutileza, criando ambiguidades não resolvíveis no campo das certezas. "Portanto, nos seus contos, paralelamente ao que acontece, há sempre o que parece estar acontecendo" (GOTLIB, 2006, p. 56). Segundo Alfredo Bosi (apud GOTLIB, 2006, p. 56), em Machado de Assis desnuda-se o terrorista que se finge de diplomata.

A exposição de Nádia Gotlib não busca selecionar a mais correta teoria do conto, aquela que deve ser defendida como verdade absoluta, pois, no que diz respeito a esse gênero textual, não é possível. A autora conclui afirmando magistralmente a singularidade do conto: "Cada conto, um caso". Isto é, cada texto, cada conto singular, precisa ser estudado em sua singularidade e em relação ao seu caráter de particularidade, que é o campo de mediação entre o singular e o universal (LUKÁCS, 1978).

Além disso, são modos peculiares de uma época da história. E modos peculiares de um autor, que, deste e não de outro modo, organiza a sua estória, como organiza outras, de outros modos, de outros gêneros. Como são também modos peculiares de uma face ou de uma fase da produção deste contista, num tempo determinado, num determinado país. A sequência dos elos que motivam a ocorrência de um conto tende, também, ao desdobramento, em mil e uma contingências (GOTLIB, 2006, p. 56).

Dessa maneira, é pela ligação do conto com a vida em cada caso singular que este pode (e deve) ser usado na escola como um instrumento pedagógico, desde que não haja tentativa de manipular o efeito do conto, mas propiciar instrumentalização para que a arte faça seu papel. 


\section{Clube do Livro: proposta pedagógica para educação literária}

O Clube do Livro realiza-se desde 28 de fevereiro de 2014. A cada semestre é organizado um calendário que procura oportunizar o contato dos estudantes participantes com variadas obras literárias. Anualmente são realizados, também, encontros para leituras de obras específicas. Em 2014, a obra lida foi O inimigo do povo, de Henrik Ibsen. O manifesto do partido comunista, de Karl Marx e Friedrich Engels, foi a obra escolhida para 2015, já em formato de minicurso. No contexto das ocupações das escolas estaduais cearenses pelos estudantes secundaristas, em 2016, foi realizado um minicurso sobre $A$ revolução dos bichos, de Georg Orwell, por compreender que a obra tinha uma temática que, além de interessar aos estudantes, possuía ligação direta com o momento histórico em que viviam.

Como dito anteriormente, o projeto desenvolve encontros periódicos para debates acerca de leituras prévias realizadas pelos membros do grupo, através de leitura compartilhada, um termo presente em práticas pedagógicas que visam ler e discutir coletivamente textos e/ou obras literárias completas. Não é uma metodologia fixa, mas prática flexível a diferentes contextos.

Esse método funciona, então, como o compartilhamento da experiência de leitura de cada membro do grupo com os demais, objetivando incentivar não somente o hábito da leitura, mas, também, o costume de analisar criticamente o lido, relacionando-o a outros tipos de conhecimentos e à prática social coletiva. Quando se advoga aqui que o trabalho realizado é coletivo, parte-se da noção de grupo não apenas como um agrupamento que compartilha espaço e que tem objetivos em comum, mas como um coletivo que tem clareza de que para alcançar os objetivos é preciso implementar ações articuladas (MARTINS, 2016, p. 296).

A escolha pelo gênero conto não é aleatória, mas pautada nas possibilidades de ligação da literatura com a prática social do educando, direcionamento que fundamenta o projeto Clube do Livro. Com a exposição da primeira parte deste artigo, justifica-se a escolha do gênero conto para um projeto específico: 1) o gênero curto facilita o interesse dos alunos pela leitura; 2) o efeito do conto gera uma relação positiva com a leitura; 3) a ligação do conto (reflexo artístico da vida) com a própria vida é percebido de forma mais direta. Além dos fatores acima, a facilidade de distribuição dos textos para os alunos foi levada em consideração, proporcionando que todos tivessem acesso ao texto impresso. Adiante, retratam-se o planejamento e a execução do projeto.

\section{Vencer por "nocaute": o efeito do conto}

Segundo Lukács (1982), a arte parte da vida cotidiana e a esta retorna, engrandecendo o olhar do indivíduo perante o seu próprio viver, permitindo que haja, na pessoa, um salto qualitativo, uma ampliação dos horizontes de 
sentido. Para que esse efeito possa se concretizar, é indispensável que o indivíduo tenha condições de apreender o conhecimento do mundo e o autoconhecimento de si que o contato com a arte proporciona. Para o objeto arte, é preciso que se tenha um sujeito capaz de apreendê-la.

Marx (2010), nos Manuscritos econômico-filosóficos de 1844, explica que não há objeto sem sujeito. Um objeto só se objetiva, segundo Lukács (2012), nas suas relações, portanto, um objeto que não estabelece relações - e as relações são estabelecidas por homens - é um não ser. Nesse sentido, o homem capaz de fruir a arte foi construído historicamente à medida que a arte era consolidada como objeto. Assim, os sentidos humanos, segundo Marx (2010), que hoje captam o mundo exterior e as obras de arte, foram constituídos ao longo do processo histórico de "fazer-se homem do homem" (LUKÁCS, 2012), através de sua capacidade de transformar conscientemente a natureza, ou seja, de realizar trabalho.

Pedagogicamente, o Clube do Livro é uma ação que se enquadra na Pedagogia Histórico-Crítica (SAVIANI, 2008) por compreender que: a) nenhuma prática pedagógica está isenta de uma teoria que a sustente, mesmo que esta não esteja explícita e que as pessoas que a executam não a reconheçam; b) toda prática pedagógica deve partir da prática social de educadores e educandos e a essa retornar de forma que seus membros estejam mais enriquecidos de conhecimentos acerca dessa prática; c) a prática pedagógica na escola pública deve situar-se no interesse da classe trabalhadora.

Esse projeto insere-se mais especificamente no momento da Pedagogia Histórico-Crítica que Saviani (2009, p. 64) chamou de instrumentalização $o^{1}$ : "Trata-se da apropriação pelas camadas populares das ferramentas culturais necessárias à luta social que travam diuturnamente para se libertar das condições de exploração em que vivem". À classe trabalhadora é negado o acesso à arte e, nesse caso particular, à literatura, portanto o projeto Clube do Livro proporciona aos estudantes e à comunidade escolar não somente acesso às obras literárias, mas aos conhecimentos necessários para lê-las, daí a necessidade de uma fundamentação teórica para a execução do projeto.

O gênero conto foi escolhido para nova etapa de encontros do Clube do Livro, justamente, por proporcionar uma experiência enriquecedora com a arte e sua relação com a realidade. Segundo Cortázar (1999), falando de literatura e usando como analogia uma luta de boxe, o romance ganharia por pontos, o conto ganharia por nocaute. Dessa forma, o Clube do Livro objetiva dois movimentos nessa etapa: proporcionar a leitura de contos e a experiência do leitor com o nocaute que o conto causa, bem como instrumentalizar os participantes de conhecimentos que permitam

\footnotetext{
1 A Pedagogia Histórico-Crítica apresenta como momentos a prática social, como ponto de partida e de chegada, a problematização, a instrumentalização e a catarse. Tais momentos não são uma sequência fechada, mas uma compreensão dialética da práxis pedagógica que objetiva levar o aluno da síncrese (compreensão caótica do todo) à síntese de múltiplas determinações da realidade (SAVIANI, 2008).
} 
a compreensão literária dos contos. Isto é, a discussão acerca da teoria do conto, do contexto do autor e da época, o debate sobre as intenções do autor e as impressões dos leitores, dentre outros.

Como explicitado anteriormente, a metodologia para tanto é a discussão após a leitura compartilhada, não uma aula expositiva sobre a teoria do conto, apesar de que o estudo teórico foi necessário à elaboração e execução do projeto por parte de seus organizadores. Os encontros não visam substituir a experiência leitora nem direcionar os resultados dessa. Por isso mesmo, a leitura dá-se antes do debate. O papel exercido pelo professor é de mediação. Assim, munido dos conhecimentos teóricos, pode ir apresentando aos estudantes tais conhecimentos numa articulação com a prática de cada um.

Como atividade externa à sala de aula, o professor se posiciona como um participante do grupo, mas não se exime de sua condição de possuidor de uma síntese mais apurada do conhecimento. Não se defende aqui qualquer apagamento do papel do professor: a postura de partícipe do grupo não anula a condição de docente, que faz uma elaboração teórica daquilo que os alunos ainda estão captando empiricamente.

Os encontros então são divididos em cinco momentos e em cinco temáticas, a saber: a) "Vencer por nocaute": o efeito do conto e a análise de "A corista" e "O capote"; b) O terror cósmico de H. P. Lovecraft; c) Machado de Assis: o mestre do conto; d) Contos fantásticos cearenses: para além da realidade; e e) Edgar Allan Poe e $o$ efeito do conto. Cada encontro é conduzido por um convidado que não necessariamente seja especialista na temática selecionada, mas que tenha afinidade com o tema, pois o Clube do Livro defende a ideia de que, ao falar de uma literatura que ama, o condutor consegue despertar o interesse da plateia, assim como Nabokov executava suas aulas:

Seu método consistia essencialmente em fazer com que os alunos compartilhassem de seu entusiasmo com a bela escrita, envolvendo-os numa realidade diferente, que é tão real por ser uma imagem artística. Trata-se, assim, de aulas muito pessoais, que enfatizam uma experiência a ser dividida (BOWERS apud NABOKOV, 2015, p. 13).

A possibilidade pedagógica do conto está circunscrita nele mesmo, não na ação, também pedagógica, do professor realizada externamente. Lukács, diversas vezes, adverte, usando as palavras de Croce, que a arte educa enquanto arte, não enquanto arte educativa, ou seja, o conto é pedagógico em si mesmo, se por pedagógico entende-se algo que transmite um conhecimento sobre a realidade. A ação do grupo, do compartilhamento da leitura, funciona analogamente à tarefa docente: medeia a relação entre educando e conhecimento, já que organizadores e convidados possuem uma visão sintética acerca dos temas abordados e do gênero conto. 
Sobre o conto, Cortázar (1999, p. 348) afirma que

[...] um conto em última instância, se desloca no plano humano em que a vida e a expressão escrita da vida travam uma batalha fraternal, se me permitem o termo; e o resultado dessa batalha é o próprio conto, uma síntese viva e ao mesmo tempo uma vida sintetizada, algo como o tremor de água dentro de um cristal, a fugacidade numa permanência.

A supracitada afirmação de Cortázar expõe as semelhanças com a concepção de arte apresentada até aqui: a arte figura a realidade e também uma parte da realidade que, de forma nenhuma, está desvinculada da totalidade social à qual pertence. Lukács (1982) nomeia a totalidade figurada na obra de arte de totalidade intensiva por intensificar em sua mimese uma parte da totalidade social, permitindo um olhar centrado do receptor. O conto literário faz justamente essa relação dialética entre a totalidade intensiva e a totalidade social. No conto, o papel da arte está dado imediatamente, inclusive, ao analisar sua composição, sua forma.

Outra analogia de Cortázar (1999, p. 350-351), que remete ao que se argumenta aqui, segue abaixo:

Neste sentido, o romance e o conto podem ser comparados analogicamente com o cinema e a fotografia, posto que um filme é em princípio uma "ordem aberta", romanesca, ao passo que uma fotografia bemsucedida pressupõe uma rígida limitação prévia, imposta em parte pelo reduzido campo que a câmera abarca e pela maneira como o fotógrafo utiliza esteticamente tal limitação.

E ainda:

Fotógrafos da qualidade de um Cartier-Bresson ou de um Brassaï definem sua arte como um aparente paradoxo: o de recortar certo fragmento da realidade, fixando-lhe determinados limites, mas de maneira tal que esse recorte opere como uma explosão que abra de par em par uma realidade muito mais ampla, como uma visão dinâmica que transcende espiritualmente o campo abarcado pela câmera.

O conto bem-sucedido realiza no leitor o efeito, nos termos de Poe, apresentado neste artigo anteriormente. Segundo Lukács (1982), a arte realiza no homem a catarse que é justamente o momento do salto qualitativo. O homem quando está imerso na cotidianidade, ocupado de suas tarefas diárias, não pode se voltar para uma leitura elevada do mundo com facilidade. A arte proporciona a esse homem um afastamento necessário a seu engrandecimento como ser social. Depois de uma catarse estética, o indivíduo não é mais o mesmo. É qualitativamente diferente. Retorna à 
vida cotidiana fragmentária e heterogênea, mas retorna diferente, com outras possibilidades de entendimento desse mesmo cotidiano.

Esse material para o contista, os temas, estão no mundo. "Um conto é significativo quando quebra seus próprios limites com uma explosão de energia espiritual que ilumine bruscamente algo que chega muito além do pequeno e às vezes miserável episódio que conta" (CORTÁZAR, 1999, p. 352). Tchekhov é mestre em contar episódios aparentemente simplórios que nada dizem, mas que figuram o mundo em suas relações: "[...] algo neles explode enquanto os lemos, propondo uma espécie de ruptura do cotidiano que vai muito além do episódio relatado" (CORTÁZAR, 1999, p. 353).

O trabalho com contos, então, justifica-se pelo que foi exposto até aqui. A escolha de contos clássicos universais e brasileiros se justifica pela qualidade. E a fundamentação teórica ora apresentada exclui a escolha de quaisquer contos que não realizem por si mesmos o papel da arte. Nisso não cabe nenhuma demagogia no sentido de defender que os filhos da classe trabalhadora não são capazes de fruir tal literatura, tendo em vista que foi apontado aqui que o papel pedagógico da instrumentalização é fundamental para o sucesso do projeto. Cortázar (1999, p. 361) apontou com lucidez o que se apresenta por trás de posições dessa natureza:

Cuidado com a fácil demagogia de exigir uma literatura acessível a todo mundo! Muitos dos que a apoiam não têm outra razão para fazê-lo além de sua evidente incapacidade para compreender uma literatura de maior alcance. [...] Não tem sentido falar de temas populares simplesmente. Os contos sobre temas populares só serão bons se se ajustarem, como qualquer outro conto, à exigente e difícil mecânica interna que tentamos mostrar na primeira parte desta palestra.

Obviamente, Cortázar não é ingênuo:

Naturalmente, seria ingênuo pensar que toda grande obra pode ser entendida e admirada pelas pessoas simples; não é assim, e não pode ser. Mas a admiração provocada pelas tragédias gregas ou as de Shakespeare, o apaixonado interesse despertado por muitos contos e romances nada simples ou acessíveis deveriam fazer os partidários da mal chamada "arte popular" suspeitarem que sua noção de povo é parcial, injusta e, em última instância, perigosa.

É nesse momento faz a defesa de que educar as pessoas para acessar a literatura é um trabalho que o autor peagógico, não literário. Dessa forma, o projeto Clube do Livro, realizado em parceria com do Pibid/Uece - Filosofia, busca oferecer essa educação de que fala Cortázar aos filhos da classe trabalhadora, não como um favor, mas como um direito que deve ser assumido pelo Estado. 


\section{Clube do Livro: planejamento e execução}

As atividades do Clube do Livro tornam-se possíveis porque aqueles que o mantêm vivo possuem um objetivo em comum a ser alcançado: contribuir para a emancipação da classe trabalhadora. O planejamento e o estudo para fundamentação teórica aqui apresentados constituíram o processo de elaboração do projeto entendido como "[...] a capacidade humana para antecipar idealmente o produto a ser alcançado pelas ações dos indivíduos" (MARTINS, 2016, p. 295). Dessa forma, é uma ação que se insere numa luta social maior, a da classe trabalhadora.

Não poderia ser diferente, tendo em vista que não há ação pedagógica neutra. Há, subjacente a toda práxis docente, uma teoria que a fundamenta, por mais que não seja explícita. Explicar, conhecer a fundamentação de sua prática, é parte indispensável do ato de ensinar. Assim, o Clube do Livro se situa como uma atividade ligada à Pedagogia Histórico-Crítica. Isso significou partir da prática social comum a alunos, professores e convidados, identificando nessa a falta de contato dos estudantes secundaristas com o gênero conto e compreendendo que este pode contribuir, por sua própria natureza, para a construção de uma perspectiva crítica do real no indivíduo.

Em seguida, deu-se um processo de problematização da prática social que visou perceber quais questões seriam necessárias ao desenvolvimento do projeto com o conto, especificamente: "Quais as teorias sobre o conto? Quais as críticas a essas teorias? Quais as características do conto? Quais temáticas poderiam ser desenvolvidas nos encontros? Quais autores seriam selecionados?". Nessa fase, deu-se, grosso modo, a organização propriamente dita de um projeto político-pedagógico do Clube do Livro e a seleção dos conteúdos necessários aos educandos para alcançarem uma visão sintetizada do conto, permitindo alguns elementos para fruir a leitura.

A instrumentalização correspondeu aos cinco encontros realizados, nos quais procurou-se permitir a fruição individual e solitária do conto. Em seguida, juntamente com o debate de cada conto e teorizações relativas a cada texto e/ou contista discutido, possibilitou-se a aquisição de conhecimento por parte do aluno, e a transmissão, por parte dos professores e convidados, ocorreu de maneira fluida, leve e descontraída - o que, de modo nenhum, significa não planejada, espontânea e não científica. O que este texto demonstra é o oposto: o caráter científico-pedagógico do Clube do Livro.

Não se pôde avaliar a síntese alcançada pelo aluno de forma pontual, mas apenas na processualidade, por meio da observação da evolução dos comentários e da participação nos debates, além de uma avaliação coletiva ao final dos encontros sobre execução e qualidade destes.

Metodologicamente, o trabalho com o conto poderia ter sido feito de maneira tradicional, em sala de aula, por meio de aulas expositivas. Decidir qual metodologia usar para determinado conteúdo do conhecimento é discutir 
a relação dialética entre conteúdo e forma (MARTINS, 2016, p. 297). Nesse caso, a forma tenta aproximar-se da leitura fluida do conto.

Como dito anteriormente, é função da escola propiciar acesso aos bens culturais e aos conhecimentos mais elevados produzidos pela humanidade. Por mais bem intencionadas que sejam as ações pontuais partidas de ações individuais e/ou coletivas, é preciso ter em mente que estas não podem substituir as ações do Estado.

\section{Considerações finais}

O conteúdo de literatura, no Brasil, baseia-se na história da literatura e é desenvolvido pela assimilação de fatos históricos, obras literárias e seus autores. A experiência com esses livros é vivida pela leitura de trechos disponibilizados em material didático. Esse contexto não oferece condições aos professores de Literatura de oferecer aos estudantes experiências mais pessoais e debates mais aprofundados sobre o objeto literário. Apesar de defender a importância da literatura para a formação do indivíduo, a falta de condições aliada à falta de interesse de alguns profissionais e do estado limitam o desenvolvimento da leitura nos estudantes.

O Clube do Livro tem sido relevante tanto para os profissionais que o organizam quanto para os demais membros que o executam, pois, para os primeiros, proporciona ampliação das práticas pedagógicas para além do currículo predeterminado e do espaço físico da sala de aula, relação mais próxima com os estudantes para construção de diálogos. Enfim, causa um enriquecimento profissional e pessoal, apesar do aumento da carga de trabalho. Para os estudantes, como já elencado no texto, gera experiências mais ricas com a leitura, acesso às obras e aos conhecimentos literários para fruir a leitura com maior qualidade.

Estudo sistemático das práticas pedagógicas é atitude fundamental para que o professor pense seu cotidiano, seus objetivos. Não é, entretanto, uma ação simples, tendo em vista as condições que permeiam a prática docente. O planejamento e a execução de projetos propiciam uma reflexão sobre o fazer docente que não está tão claro no planejamento das atividades cotidianas do professor. Foi bastante relevante fazê-lo. Espera-se que essa experiência possa ser reproduzida com bons resultados em outros contextos escolares, ainda que não haja uma política pública de acesso aos bens culturais.

\section{Referências}

BOWERS, Fredson. Introdução. In: NABOKOV, VLADIMIR. Lições de literatura. Tradução de Jorio Dauster. São Paulo: Três Estrelas, 2015, p. 9-22. 
CORTÁZAR, Julio. Alguns aspectos do conto. In: CORTÁZAR, Julio. Obra crítica, v. 2. Tradução de Paulina Wacht e Ari Roitman. Rio de Janeiro: Civilização Brasileira, 1999, p. 345-363.

GOTLIB, Nádia Battella. Teoria do conto. Série princípios, 2. São Paulo: Editora Ática, 2006.

LUKÁCS, György. Introdução a uma estética marxista: sobre a particularidade como categoria da estética. Tradução de Carlos Nelson Coutinho e Leandro Konder. 2. ed. Rio de Janeiro: Civilização Brasileira, 1978.

LUKÁCS, György. Para uma ontologia do ser social I. Tradução de Carlos Nelson Coutinho, Mario Duayer e Nélio Schneider. São Paulo: Boitempo, 2012.

MARTINS, Lígia Márcia. Reflexões acerca da prática pedagógica. In: ZIENTARSKI, Clarice; PEREIRA, Karla Raphaella Costa; FREIRE, Perla Almeida Rodrigues (Org.). Escola da Terra: conhecimentos formativos para a práxis docente do/no campo (quem organizou?) Assis: Triunfal Gráfica e Editora, 2016. p. 293-302.

MARX, Karla. Manuscritos econômico-filosóficos. Tradução de Jesus Ranieri. São Paulo: Boitempo: 2010.

SAVIANI, Dermeval. Escola e democracia: teorias da educação, curvatura da vara, onze teses sobre a educação política. 41. ed. Campinas: Autores Associados, 2009. (Coleção Polêmicas do Nosso Tempo, 5).

SAVIANI, Dermeval. Pedagogia histórico-crítica: primeiras aproximações. 10. ed. Campinas: Autores Associados, 2008.

THIOLLENT, Michael. Metodologia da pesquisa-ação. 5. ed. São Paulo: Cortez, 1992.

Recebido em: outubro/2017

Aceito em: abril/2018

\section{Endereço para correspondência:}

Karla Raphaella Costa Pereira $<$ karla raphaella@hotmail.com>

Rua Coronel Guilherme Alencar, 767 - Messejana

60840-340, Fortaleza, CE, Brasil 